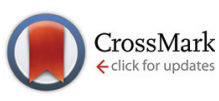

Cite this: Dalton Trans., 2016, 45 4090

Received 9th September 2015, Accepted 3rd November 2015

DOI: $10.1039 / \mathrm{c} 5 \mathrm{dt} 03522 \mathrm{~h}$

www.rsc.org/dalton

\section{Origin of highly active metal-organic framework catalysts: defects? Defects!}

\author{
J. Canivet, ${ }^{a}$ M. Vandichel ${ }^{a, b}$ and D. Farrusseng ${ }^{\star a}$
}

\section{Introduction}

Metal Organic Frameworks (MOFs) are the latest discovered class of nanoporous crystalline materials. ${ }^{1-7}$ The discovery of the first examples in the late 90s has excited researchers in catalysis. ${ }^{8-13}$ Because of their similarity with zeolites in terms of pore size and pore structures, it was acknowledged that MOFs could achieve breakthroughs in catalysis for the energy and chemistry sectors. ${ }^{14,15}$ Although we can observe a continuous increase of scientific research papers published on catalytic MOFs (growth annual rate of $30 \%$ since 2007), their numbers represent only a minor fraction $(10 \%)$ of the total number of papers dealing with MOFs. Regardless of their intrinsic lower chemical and thermal stability, their inertness with respect to hydrocarbons prevents them from being applied as catalysts in refinery applications. ${ }^{16}$ In 2007 , Corma et al. made the acknowledged statement that "the potential of MOFs is largely hampered by the fact that the coordination sphere of the metal ion is usually completely blocked by the organic linkers". ${ }^{14}$ One year later, we published in the New Journal of Chemistry a study on the role of defect sites in MOF-5 which are at the origin of its catalytic activity. ${ }^{17}$ Since then, a number of striking examples have been reported on their outstanding catalytic activities and selectivity. In all cases, authors were intrigued as it was unexpected when looking at the ideal structure and composition from crystallo-

\footnotetext{
${ }^{a}$ CNRS/University Lyon-1, IRCELYON, 2. Av Albert Einstein, 69626 Villeurbanne, France. E-mail: david.farrusseng@ircelyon.univ-lyon1.fr

${ }^{b}$ Center for Molecular Modeling, Universiteit Gent, Technologiepark 903, B-9052 Zwijnaarde, Belgium
}

graphic data and keeping in mind Corma's statement. Remarkably, the presence of defects e.g. ligand or linker vacancies, even hardly detectable, was raised as the main origin of unexpected catalytic activities. Notwithstanding the usefulness of post-functionalisation for the design of MOF-based heterogeneous catalysts, ${ }^{18-21}$ we are focussing here on the catalytic behaviour driven by metal nodes.

In the first part of this review, we will present striking and representative examples of the origin and roles of MOF defects in catalysis. Instead of an exhaustive enumeration, carefully selected and relevant examples are discussed in a comprehensive manner in order to highlight the general concepts which can be applied for the rationalisation of MOF defects in catalysis. The second part of the review will show methods for generating controlled defects in MOFs for application in catalysis. Importantly, we will show in this review that for a number of reactions of industrial relevance, MOFs outperform zeolites and even state-of-the-art catalysts. In all cases their catalytic properties find their origin from defects in a general sense.

\section{Relevant defects in heterogeneous catalysis}

The presence of defects in solids plays a major role in heterogeneous catalysis which can be either positive or negative with regard to performances. A well known example in catalysis among others is the doping of crystalline mixed oxides. The addition of a minor fraction of zirconium $(\mathrm{Zr})$ in ceria oxide $\left(\mathrm{CeO}_{2}\right)$ yields a catalyst $\left(\mathrm{ZrCeO}_{4}-\delta\right)$ with outstanding catalytic properties which are due to the stabilisation of oxygen 
A)

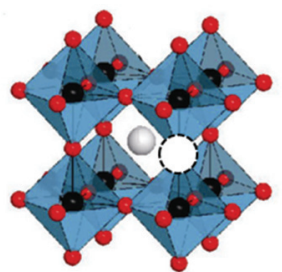

oxygen vacancy

B)

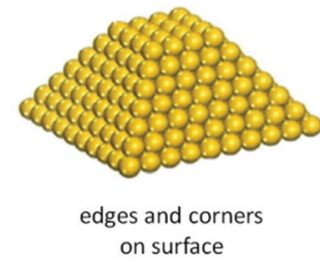

on surface

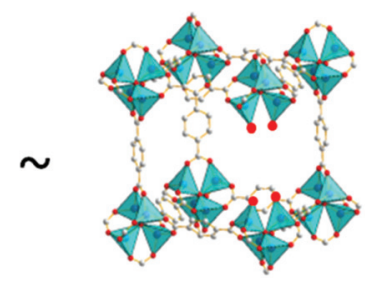

missing linker

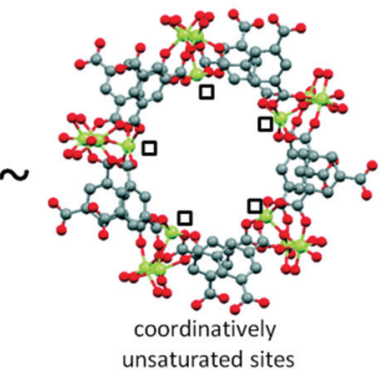

Fig. 1 Analogy between defects in classical heterogeneous catalysts and MOF structures.

deficient structures. By extension in the world of MOFs, this oxygen vacancy could be regarded as a missing linker in the framework (Fig. 1A).

At the crystal scale, although X-ray diffraction refinements indicate solid solutions for the whole $\mathrm{ZrO}_{2}-\mathrm{CeO}_{2}$ phase diagram, it is now acknowledged that the addition of $\mathrm{Zr}$ creates distortion leading to localised defects in the crystallites. $^{22}$ Crystalline defects were also characterised in MOF single crystals. ${ }^{23,24}$ Fischer et al. have depicted defective MOFs from a solid-state point of view in a recent comprehensive and exhaustive review which also addresses the consequence on various properties such as luminescence and magnetism. ${ }^{25}$

On the other hand, the comparison of MOFs with bulk crystalline solids is not the most appropriate for catalysis. Indeed, heterogeneous catalysis is firstly a surface science as the mechanism of bond breaking and forming with substrates occurs at the solid surface. In addition, MOFs exhibiting permanent and high porosity can be regarded as an extended surface as (almost) all atoms can be accessible from the gas phase. Therefore, the internal surface termination of MOFs is of primary importance. For metal oxides, including zeolites, their surface can be terminated by hydroxyl groups which confer them Brønsted type acidity. ${ }^{26-28}$ For electron poor noble metals, the coordinatively unsaturated atoms present at the particle surface are typical Lewis catalytic sites. The example of gold has become famous. It was believed for a long time that gold was inert in catalysis. ${ }^{29}$ However, in nanometric particles for which the surface atoms have low coordination numbers, gold shows intrinsic catalytic properties (Fig. 1B). Hence, for metal and oxide solids, the increase of the surface by division of the matter creates sites which are responsible for the catalytic properties. Conceptually, surface termination, usually vacancies or hydroxyl groups, could be regarded as defects if one keeps in mind the ideal long range order structure as determined by bulk characterization techniques such as X-ray diffraction.

Hence, MOFs can appear at the frontier of solid state chemistry because of their long range order which defines the porous network and because of surface science as all atoms are at the surface. In the following, we will show that the same concept of vacancy (e.g. lower coordination number) and hydroxyl terminated surface can be applied for the definition of MOF defects which are relevant to explain the observed, yet "unexpected" catalytic results. ${ }^{30}$

\section{Lewis acido-basicity}

Lewis acidity in MOFs corresponds to an accessible metal site with a low coordination number, also known as coordinatively unsaturated sites (cus). They are obtained by the removal of labile ligands which usually are water molecules or electron donor solvents such as alcohols or dimethylformamide (Fig. 2). This selective removal of a ligand can be achieved by a soft thermal treatment under dry conditions. Thermal pretreatment for heterogeneous catalysts for liberating the catalytic sites is a very usual process and is commonly coined activation.

\section{Activation by removing labile ligands}

Metal organic frameworks made from dimeric transition metal clusters are representative examples of Lewis acid MOFs. ${ }^{32,33}$ HKUST-1, of the formula $\mathrm{Cu}_{3}(\text { btc })_{2} \cdot 3 \mathrm{H}_{2} \mathrm{O}$ consists of a dimeric copper unit which is bridged by four carboxylate moieties from four BTC linkers, resulting in a characteristic paddlewheel moiety. Each copper atom is octahedrally coordinated by four oxygens and one copper atom. Soft thermal treatment removes the solvent ligands (here water) to leave a vacant coordination site (cus) as a Lewis acid which has been characterised by the adsorption of molecular probes followed by IR spectroscopy. ${ }^{34,35}$
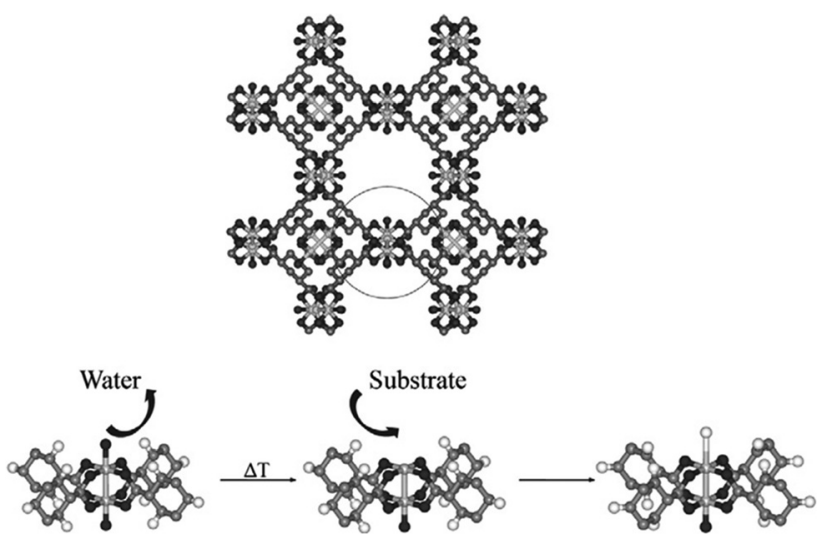

Fig. 2 HKUST-1 porous structure (top) $\mathrm{Cu}_{2}$ Paddle-wheel showing terminal water molecules, thermal activation affords Lewis sites by water removal allowing substrate activation on the vacancy from ref. 31 . 

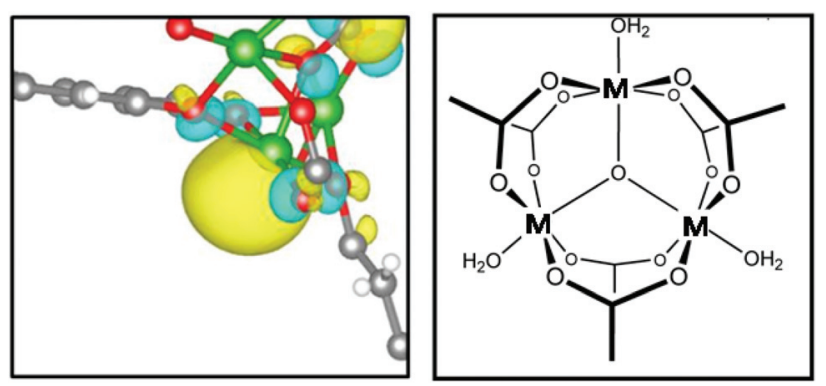

Fig. 3 Lewis sites: metal trimer showing water molecules as a labile ligand (right) and volume of the orbital of Ni of CPO-27 (MOF-74) as calculated by DFT from ref. 41 (left).

Kaskel et al. have reported the first example of catalytic applications on the cyanosilylation of carbonyl compounds. ${ }^{36}$ Since then, the Lewis acidity of $\mathrm{Cu}_{3}(\mathrm{btc})_{2}$ and other $\mathrm{Cu}$-based MOFs has been demonstrated for the isomerization of $\alpha$-pinene oxide and the cyclization of citronellal. ${ }^{37}$ Beyond Lewis acido-basicity, MOFs made of open transition metal sites have been applied in redox type catalysis such as selective oxidation of xanthenes ${ }^{38}$ and hydrochinone ${ }^{39}$ and the epoxidation of olefins. ${ }^{40}$ Among the striking examples, we can highlight the hydroxylation of aromatics ${ }^{31}$ which has shown the highest turnover frequencies reported so far.

A series of MOFs exhibiting Lewis sites including HKUST-1 (Cu), CPO-27(Ni) (also known as MOF-74), STA-12(Ni) ${ }^{42,43}$ and MIL-100(Sc) were screened for various catalytic reactions (Fig. 3). ${ }^{44}$ The MIL-100(Sc) is isomorphous to the famous MIL-100 originally constructed with $\mathrm{Cr}^{3+}$ trimers. ${ }^{45}$ In the scandium version the $\left[\mathrm{Sc}_{3} \mathrm{O}\left(\mathrm{O}_{2} \mathrm{C}-\mathrm{R}\right)_{6}(\mathrm{OH})\left(\mathrm{OH}_{2}\right)_{2}\right]$ trimers can lose coordinated water to leave five-fold coordinated scandium cus. It was reasoned to be a strong Lewis acid catalyst as scandium triflate is a well-known molecular Lewis catalyst. ${ }^{46}$ When compared to other mentioned MOFs, dehydrated MIL-100(Sc) was confirmed to be a strong Lewis acid by $\mathrm{H}_{2}$ adsorption followed by infrared spectroscopy. ${ }^{47}$ The MIL-100 (Sc) shows $100 \%$ conversion and selectivity for an intermolecular carbonyl ene reaction whereas zeolite beta and scandium beta are much less active and selective.

Similarly, Opanasenko has systematically compared the performances of HKUST-1(Cu) and MIL-100(Cr) with zeolites in a series of acid-catalyzed test reactions (Pechmann and Knoevenagel condensations, acylation, Beckmann rearrangement and Prins annulation reactions)..$^{48}$ Although it is not possible to infer a Lewis mechanism for all the cases, one can still observe that in many cases MOFs show higher activity and/or selectivity than zeolites.

\section{Activation by dehydration}

We focus here on UiO-66 which shows peculiar properties. The structure of UiO-66 consists of $\mathrm{Zr}_{6} \mathrm{O}_{4}(\mathrm{OH})_{4}$ inorganic cornerstones bridged to another by terephthalate linkers. ${ }^{49,50}{\mathrm{Six} \mathrm{Zr}^{4+}}^{4}$ cations in the $\mathrm{Zr}_{4} \mathrm{O}_{4}(\mathrm{OH})_{4}$ unit are located at the vertices of a $\mathrm{Zr}_{6}$ octahedron, on which $4 \mu_{3}-\mathrm{O}$ and $4 \mu_{3}-\mathrm{OH}$ alternatively cap

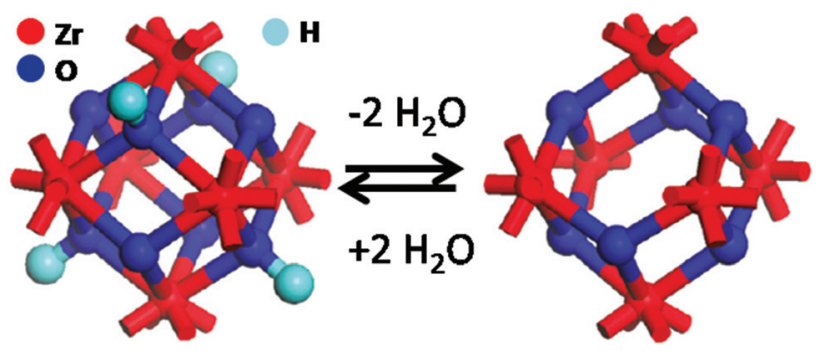

Fig. 4 Principle of the activation of UiO- 66 by a reversible dehydration/ dehydroxylation process. The thermal dehydration of the cornerstone $\mathrm{ZrO}_{6}(\mathrm{OH})_{4}$ (left) generates $\mathrm{Zr}_{6} \mathrm{O}_{6}$ with the corresponding coordinatively unsaturated sites (cus) from ref. 50.

the 8 faces. The two oxygen atoms of each carboxylate linker bridge the edges of a $\mathrm{Zr}_{6}$ octahedron. All the 12 edges of the $\mathrm{Zr}_{6}$ octahedron are bridged in this way so that the $\mathrm{Zr}_{6} \mathrm{O}_{4}(\mathrm{OH})_{4}$ unit results in a continuous faced-centered cubic framework structure. Upon heat-treatment at $c a .250-300{ }^{\circ} \mathrm{C}$, dehydration of the $\mathrm{Zr}_{6} \mathrm{O}_{4}(\mathrm{OH})_{4}$ cornerstone yields a new composition of $\mathrm{Zr}_{6} \mathrm{O}_{6}$ while maintaining the integrity of the porous structure (Fig. 4).

This dehydroxylation/dehydration process is fully reversible and the dissociative adsorption of two water molecules regenerates the original cornerstone. ${ }^{50}$ Vandichel proposed a mechanism of dehydroxylation which is accompanied by the reduction of the coordination number of $\mathrm{Zr}$ atoms from 8 (square antiprismatic) to 7 because of the creation of oxygen defective sites or vacancies. ${ }^{51}$ As a note, we can see that the removal of chemisorbed water either as a single molecule (case of HKUST-1) or dissociated as bridging hydroxyl (case of UiO-66) on the cornerstones yields metal cations with lower coordination numbers.

Moreover while an ideal crystalline UiO-66 material should have all $\mathrm{Zr}$ ions fully 8-fold coordinated, the study of the thermogravimetric analysis profiles tends to show that, from the 12 linkers surrounding each metal cluster, up to four are usually missing for the real solids, depending on synthesis parameters (Fig. 5, left). ${ }^{52}$ The linker vacancies are usually compensated for by chloride anions. ${ }^{53}$ However, under optimized synthesis conditions, UiO-66 with missing linkers compensated for by (dissociated) water molecules have been characterised by X-ray diffraction (Fig. 5 , center) ${ }^{54,55}$ Hence, by thermal activation, $\mathrm{Zr}$ with lower coordination numbers can be obtained at vertices by water removal. Vandichel et al. have estimated the reaction free energy of the dehydration process of a water molecule on a linker deficient UiO-66 to be about $-65 \mathrm{~kJ} \mathrm{~mol}^{-1}$ per water molecule under typical activation conditions $\left(320{ }^{\circ} \mathrm{C}, 10^{-3} \mathrm{mbar}\right)$ and thus feasible at moderate temperature (Fig. 4 , right). ${ }^{51}$

Although the $\mathrm{Zr}_{6} \mathrm{O}_{6}$ cornerstone exhibits Lewis sites which can dissociate water and thus in principle can activate other molecules, the congestion of the cornerstone, surrounded by the 12 ligands, prevents the accessibility of the sites by large reactants. ${ }^{51,52}$ Even though this is not proven experimentally yet, defect free UiO-66 shall not be in principle catalytically 


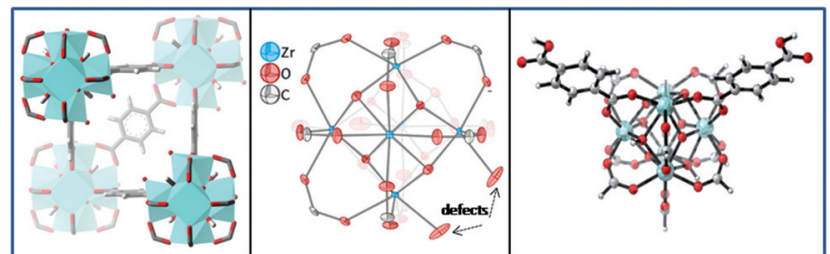

Fig. 5 Scheme of UiO-66 with a missing linker showing the enhanced accessibility (left). Two capping water molecules replace the missing linker (center) from ref. 54, and a cluster model of a dehydrated UiO-66 cornerstone with one linker vacancy from ref. 56 (right).

active for reactants bulkier than its $6 \AA$ aperture. Simulations carried out on a cluster model indicate that catalytic cyclization of citronellal can only be performed on a linker deficient UiO-66 (Fig. 5). ${ }^{56}$

In summary, while generating Lewis sites after activation treatment, the linker vacancy enables the accessibility of the reactants to the catalytic sites.

\section{Brønsted acido-basicity}

Brønsted acid sites are generated on the surfaces of zeolites when $\mathrm{Si}^{4+}$ is isomorphically replaced by a trivalent metal cation such as, for instance, $\mathrm{Al}^{3+}$. This substitution creates a negative charge in the lattice that can be compensated for by a proton. From a structural point of view, the Brønsted acid site in a zeolite can be seen as a resonance hybrid of structures I and II as shown in Fig. 6. Structure I contains a fully bridging oxygen with a weakly bonded proton while structure II is a silanol group with a weak Lewis acid interaction of the hydroxyl oxygen with an Al. It is generally acknowledged that model I would better represent the situation of the acid site in a crystalline zeolite structure, while model II would represent the situation in an amorphous silica-alumina where no stabilization by long-range symmetry exists. ${ }^{26}$ Because of this resonance and the usual co-existence of both forms, their respective roles in catalysis are hardly unravelled.

In this section, we will see that, in MOF with linker vacancies, the cornerstones can be hydroxylated which may confer Brønsted or Lewis acidity depending on substrates.

\section{Friedel-Crafts reaction}

The alkylation of aromatics, also known as Friedel-Crafts reactions, is applied on a wide range of large scale processes
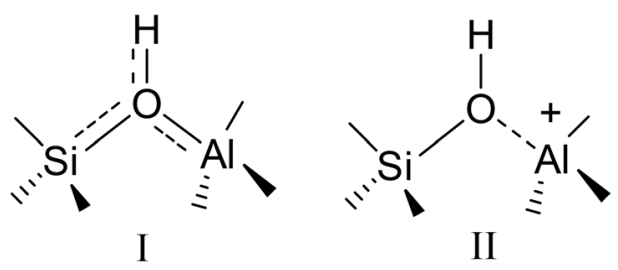

Fig. 6 Possible models for Brønsted acidity from ref. 26. in industry. ${ }^{57}$ The alkylating agents are preferentially olefins or alcohols, but alkyl- and aryl-chlorides can also be used for benchmarking. Numerous commonly used homogeneous catalysts such as strong mineral acids ( $\mathrm{HF}$ or $\mathrm{H}_{2} \mathrm{SO}_{4}$ among others) and Lewis acids $\left(\mathrm{AlCl}_{3}, \mathrm{FeCl}_{3}\right.$ or $\mathrm{ZnCl}_{2}$ among others) have continuously been replaced by $\mathrm{H}$-form zeolites. ${ }^{58}$

Ferey and coworkers have reported the catalytic activity of two different MIL-100 (Fe, Cr) for Friedel-Crafts benzylation. ${ }^{59}$ Although MIL-100(Fe) and MIL-100(Cr) have a very similar structure $\mathrm{M}_{3} \mathrm{OF}_{0.85}(\mathrm{OH})_{0.15}\left(\mathrm{H}_{2} \mathrm{O}\right)_{2}(\mathrm{btc})_{2}$, the $\mathrm{Fe}^{3+}$ containing MOF shows much higher catalytic activity that even surpasses HBEA and HY zeolites. As evidenced by $\mathrm{CO}$ chemisorption at low temperature, MIL-100 $\left(\mathrm{Cr}^{3+}\right)$ shows both $\mathrm{Cr}-\mathrm{OH}$ Brønsted sites with medium acidity and several species of Lewis centres. ${ }^{60,61}$ Under humid conditions, water molecules are coordinated to the Lewis centres, thus creating other types of Brønsted acidity. However unlike zeolites they are free from any interaction by H-bonding with adjacent oxygen and do not dissociate to form hydroxyl groups. It was unclear which type of centre is responsible for the catalytic activity, the Fe Lewis site or the bridging Brønsted site or both. Lately, Cejka et al. obtained the same conclusions on a similar reaction of xylene acylation. $^{62}$

In the framework of MOF-5, $\mathrm{Zn}_{4} \mathrm{O}$ cornerstones are linked in octahedral arrays by bdc groups which complete the coordination sphere of the $\mathrm{Zn}$ atoms. Hence, there are neither apparent nor latent possible catalytic sites (neither Lewis nor Brønsted) and little could be expected from MOF-5 in catalytic applications. The development of high throughput and parallel screening devices in the mid 2000s has enabled systematic catalytic testing of a library containing solids of all kinds, including guessed best candidates, possible challengers and even solids exhibiting a priori inappropriate profiles (e.g. MOF-5). It is in this frame that the role of defective MOFs in the origin of the catalytic activity has been discovered in 2008. ${ }^{17}$ Unexpectedly, MOF-5 prepared by fast precipitation exhibits outstanding shape selectivity for the alkylation of aromatics which overcomes reference zeolites (Fig. 7). The catalytic results and conclusions were confirmed by separate studies. ${ }^{63,64}$

Based on the concomitant structural studies of Hafizovic et al., we reasoned that the possible presence of $\mathrm{Zn}-\mathrm{OH}$

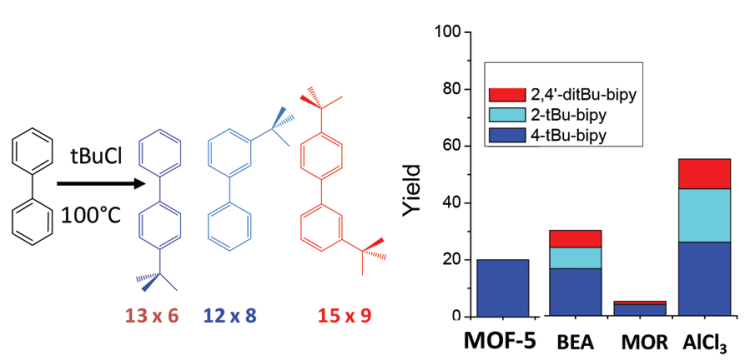

Fig. 7 Alkylation of biphenyl with tert-BuCl on MOF-5 prepared by fast precipitation. 


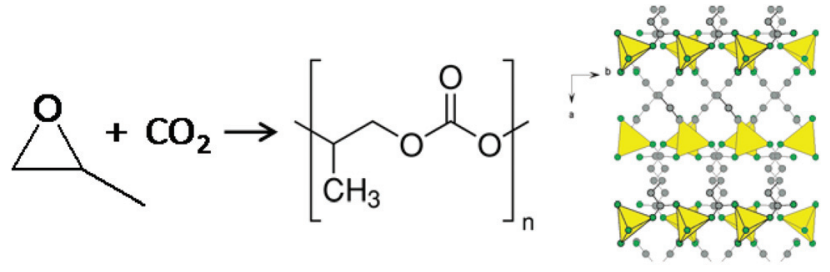

Fig. 8 Propylene oxide and $\mathrm{CO}_{2}$ copolymerization catalysed by the layered structure of zinc glutarate from ref. 74 .

species could be at the origin of the catalytic activities. ${ }^{65} \mathrm{~A}$ $10 \%$ excess of $\mathrm{Zn}$ with respect to the theoretical formulae, leads to a global composition of $\mathrm{Zn}_{4} \mathrm{O}($ bdc $) \cdot 2 \mathrm{H}_{2} \mathrm{O}+\mathrm{Zn}(\mathrm{OH})_{2}$. According to Hafizovic et al., ${ }^{65}$ zinc hydroxide nanoclusters that partly occupy the cavities could be responsible for the structure distortion evidenced by the splitting of diffraction peaks. In addition, IR and solid state ${ }^{1} \mathrm{H}$ NMR studies indicated the presence of $c a$. $4 \%$ of $\mathrm{OH}$ bridging species like those found for $\mathrm{Zn}_{3}\left(\mu_{3} \mathrm{OH}\right)_{2}(\mathrm{bdc})_{2} \cdot 2 \mathrm{DEF}$ (MOF-69C). Based on a linear reactivity trend of a series of substituted aromatics, we concluded that the intermediate is a protonated species which supports a Brønsted type mechanism. ${ }^{66}$ Llabres i Xamena came to the same conclusions by studying the Knoevenagel condensation reaction. ${ }^{30}$ The authors concluded that the unexpected catalytic properties arise from defects which can be either/and $\mathrm{Zn}-\mathrm{OH}$ or $\mathrm{ZnO}$.

A major breakthrough in the area of propylene oxide and $\mathrm{CO}_{2}$ copolymerization came with the discovery of air-stable dicarboxylic acid derivatives of zinc by Soga and co-workers. ${ }^{67}$ These catalysts were prepared by the reaction of zinc hydroxide or zinc oxide with dicarboxylic acids in toluene. Among zinc carboxylates, the zinc glutarate analogue was found to be most catalytically active, producing significant quantities of polypropylene carbonate from propylene oxide and $\mathrm{CO}_{2} \cdot{ }^{68,69}$ The structure was found to be a layered structure of zinc atoms with bridging dicarboxylates between the layers (Fig. 8). ${ }^{70,71}$ The percentage of active zinc sites on this heterogeneous catalyst was quite low $(<5 \%)$, likely because the reaction should take place at the external surface of the non-porous crystallites. In 2002, BASF researchers discovered that nanoporous zinc carboxylates prepared from trimesic acid and others can produce polypropylene carbonate with a molecular weight of ca. $M_{\mathrm{w}}=60.000-75.000 \mathrm{~g} \mathrm{~mol}^{-1} \cdot .^{72}$ Although characterization data were not provided, we can presume the presence of $\mathrm{Zn}-\mathrm{OH}$ defects as discussed above. As we will discuss later, both $\mathrm{CO}_{2}$ and oxygen containing substrate (methanol) can be activated on $\mathrm{Zn}-\mathrm{OH}$ species based on the simulation studies of Chizallet. $^{73}$

\section{Mechanisms of water-induced defect formation}

Two main mechanisms were reported by Low and coworkers, which drive the MOF framework decomposition upon water exposure, namely the ligand displacement and the hydrolysis. Both mechanisms were established from computational

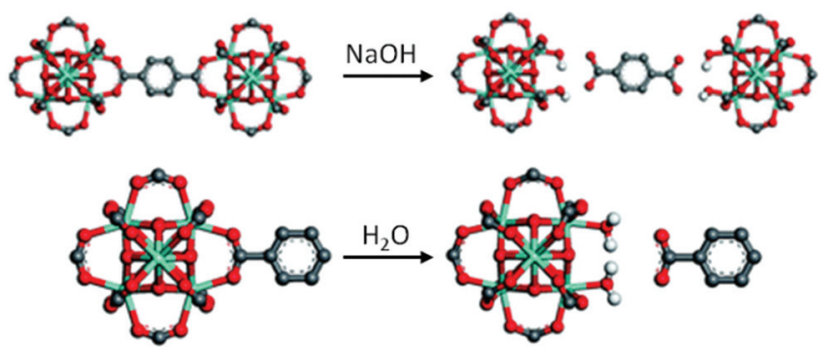

Fig. 9 Proposed ligand displacement mechanism for UiO-66 breakdown in the presence of sodium hydroxide or water. Reprinted with permission from ref. 76 .

studies and confirmed experimentally. ${ }^{75}$ The ligand displacement reaction involves the insertion of a water molecule into the $\mathrm{M}-\mathrm{O}$ metal-ligand bond of the framework. This leads to the formation of a hydrated cation and to the release of a free ligand (eqn (1)).

$$
\mathrm{M}^{n+}-\mathrm{L}^{n-}+\mathrm{H}_{2} \mathrm{O} \rightarrow \mathrm{M}^{n+}-\left(\mathrm{OH}_{2}\right) \cdots \mathrm{L}^{n-}
$$

In contrast, during the hydrolysis reaction, the metalligand bond is broken and water dissociates to form a hydroxylated cation and a free protonated ligand (eqn (2)).

$$
\mathrm{M}^{n+}-\mathrm{L}^{n-}+\mathrm{H}_{2} \mathrm{O} \rightarrow \mathrm{M}^{n+}-(\mathrm{OH})^{-}+\mathrm{HL}^{(n-1)-}
$$

Similarly, Walton and coworkers proposed a ligand displacement mechanism for the structural breakdown of ZrMOFs (UiO-66) in the presence of either sodium hydroxide or water (Fig. 9). ${ }^{76}$

From direct first-principles simulations at various water loadings, the ligand displacement was also defined as the main route for the framework decomposition of hydrophobic IRMOFs. $^{77}$ It has been found that in addition to the water molecule involved in the ligand displacement, additional water stabilized both the hydrated metal species and the displaced ligand. Coudert and coworkers furthermore reported that $\mathrm{ZnO}$ clusters act as hydrophilic defects in hydrophobic MOFs. They demonstrated that, at high water loading, the metal oxide stabilizes a water cluster in its neighbourhood which promotes the ligand displacement. Such a mechanism may explain the presence of $\mathrm{Zn}-\mathrm{OH}$ defects which are active in acid catalysis. ${ }^{17,78}$

\section{Framework termination at the external surface}

In principle, the zeolitic imidazolate framework ZIF-8, synthesized from 2-methylimidazole and a zinc precursor, contains fully coordinated $\mathrm{Zn}^{2+}$ cations without cus. In addition, it is very thermally and chemically stable as $\mathrm{Zn}$ accommodates a very favourable tetrahedral coordination. Nevertheless, the material has proven to be one of the most active catalysts for the Knoevenagel reaction. ${ }^{79}$ Even more striking, ZIF-8 outperforms state-of-the-art catalysts currently applied at the industrial level for the transesterification of triglycerides in the production of fatty acid methyl esters (FAME). In addition, 

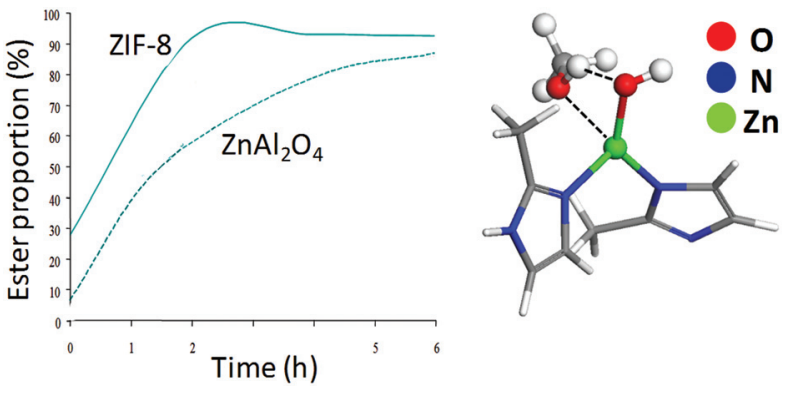

Fig. 10 Comparison of performances between ZIF-8 and state-of-theart catalysts $\left(\mathrm{ZnAl}_{2} \mathrm{O}_{3}\right)$ in the transalkylation of rapeseed oil with methanol at $200{ }^{\circ} \mathrm{C}$ (left). Activation of methanol by a $\mathrm{Zn}-\mathrm{OH}$ species on a linker deficient cornerstone, the nucleophilic oxygen of the $\mathrm{MeOH}$ links to the $\mathrm{Zn}(\mathrm{II})$ Lewis site accompanied by a protonation of the terminal hydroxide. ${ }^{80}$

there is a second and a priori obvious reason to think that ZIF-8 could not be active for this reaction. Actually triglycerides (here rapeseed oil) are far too bulky to penetrate inside the sodalite cavity of the ZIF-8 which exhibit apertures of $3 \AA$ in a hexagonal window. The only possibility for the catalytic reaction to occur is at the surface of crystallites. Supported by FTIR-monitored CO adsorption, a thermodynamic mapping of various types of surface terminations was investigated by DFT as a function of temperature and pressure. ${ }^{80}$ At the surface, several species can coexist, especially low coordination $\mathrm{Zn}$ such as $\mathrm{Zn}$ (II) species, Brønsted acid site (NH groups) together with basic sites ( $\mathrm{OH}$ groups and $\mathrm{N}$-moieties). Here also, only cornerstones with linker vacancies can activate methanol and the higher is the linker vacancy (e.g. $\mathrm{Zn}$ with lower coordination number), the stronger is the activation by a Lewis type adsorption. The study reveals the low Brønsted acidity of the terminal hydroxyl upon CO adsorption. The mechanism of methanol activation occurs on a terminal $\mathrm{Zn}-\mathrm{OH}$ moiety at a linker deficient cornerstone (Fig. 10). The nucleophilic oxygen of the $\mathrm{MeOH}$ links to the $\mathrm{Zn}(\mathrm{II})$ Lewis site while the terminal hydroxide is protonated by the $\mathrm{MeOH}$.

\section{Defect engineering}

\section{Generation of linker vacancies}

By direct synthesis. This aims at employing synthesis "tricks" that will allow the creation of linker vacancies at MOF cornerstones leading to terminal $-\mathrm{OH}$ groups, instead of a linker as they should be found in a perfect structure. Two synthesis processes have been investigated (Fig. 11). ${ }^{78}$ We reasoned that for defect free crystals, the synthesis conditions will be "thermodynamically" driven e.g. allowing time for crystal growth in a reversible self-assembly synthesis process. In a first approach, one can anticipate that a synthesis by a very fast reaction (kinetically driven) will lead to networks for which a small fraction of linkers is missing while still maintaining the original structure. This approach was undertaken

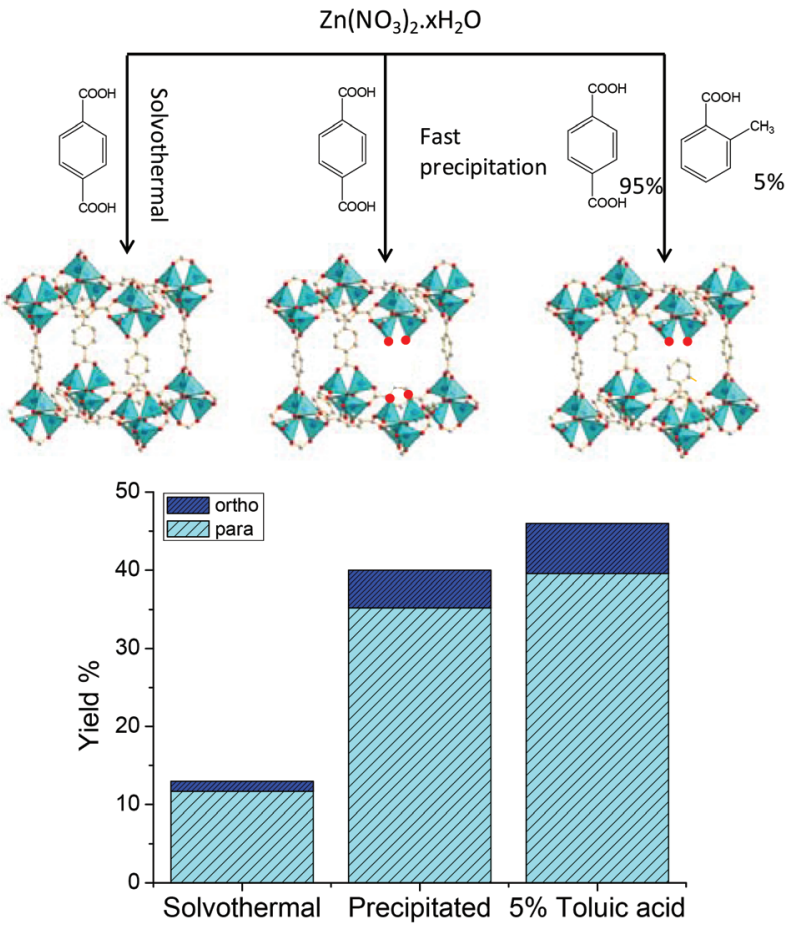

Fig. 11 Synthesis of defective MOF-5 by fast precipitation and using a dummy linker. Comparison of catalytic performances on the benzylation of toluene by comparison with a solvothermal process sample from ref. 78.

on the synthesis of MOF-5 by rapid precipitation according to a recipe published by Huang et al. (Fig. 11). ${ }^{81}$ The second approach consists of synthesizing MOF materials from a mixture of poly-dentate and mono-dentate linkers which will play the role of a "dummy linker". When present at the cornerstone, this dummy linker will lead to local "defects" at nodes which are adjacent/opposite to the mono-dentate linkers as far as a carboxylate function is missing. This approach was studied on MOF-5 by adding $5 \mathrm{~mol} \%$ of para-toluic acid into the precursor solution before the precipitation starts (Fig. 11). NMR analysis of the digested solid indicates the presence of the monocarboxylate linker at 3-5 mol\% in the final solid. The two solids obtained by fast precipitation and by using the dummy linker (also prepared by fast precipitation) were studied in the Friedel-Crafts benzylation of toluene as it was proven to reveal the presence of defects in MOF-5. The catalytic results clearly indicate that the proposed strategies actually yield "defective" MOF-5 and that the addition of dummy linkers further increases the catalytic activity (Fig. 11). For both solids, the presence of $\mathrm{Zn}-\mathrm{OH}$ species was characterized. We can also observe a residual activity on MOF- 5 prepared by a solvothermal process which should afford a defect-free solid. We believe that the very high moisture sensitivity of MOF-5 is at the origin of the creation of a small concentration of $\mathrm{Zn}-\mathrm{OH}$ species, at least at the crystal external surface. In a separate study, Llabres i Xamena et al. came to the same conclusions by studying the Knoevenagel reaction. ${ }^{30}$ The authors concluded 
that the use of fast precipitation increases the concentration of defects in MOF-5 ( $\mathrm{ZnO} / \mathrm{ZnOH})$, which leads to a higher catalytic activity.

The strategy of mixing mono and bidentate linkers for creating "on purpose"-defects in MOFs was applied in ref. 82,83 for the creation of a larger porosity, to be exploited in gas uptake applications. This process was further investigated in the case of multidentate linkers. ${ }^{83}$

Upon thermal treatment. Without assistance, the direct removal of carboxylate linker from a cornerstone upon heating can be hardly obtained without damaging the porous structure. In the case of UiO-66, Vandichel et al. have calculated a reaction free energy for the direct removal of a terephthalate linker from two $\mathrm{Zr}_{6} \mathrm{O}_{4}(\mathrm{OH})_{4}$ cornerstones and found that this reaction is unfeasible, even under activation conditions. ${ }^{51}$ On the other hand, when the cornerstone already contains another terminal ligand such as chlorine, dissociated water or a monocarboxylate (trifluoro acetate) instead of the original, a terephthalate, their removal by heat treatment becomes theoretically feasible at a temperature compatible with the thermal resistance of UiO-66, assuming a moderate linker vacancy concentration. $^{55}$ Vermoortele and co-workers demonstrated that the vacancy concentration per cluster (e.g. the Lewis site concentration) can be controlled from $c a$. 0.5 to 2 by adjusting the temperature from 150 to $300{ }^{\circ} \mathrm{C}^{52}$ Hence, the substituted terminal ligand can play the role of a leaving group upon moderate thermal treatment leading to a Lewis type cornerstone as shown in Fig. 4. Vermoortele et al. showed that the incorporation of trifluoroacetate opens up more Lewis-acidic cornerstones on model catalytic reactions. ${ }^{52}$

By linker substitution with lower coordination mode. Instead of a "dummy" linker exhibiting one carboxylate less than the ideal structure would require, it is also possible to substitute one carboxylate with a donating moiety of a different kind. Marx and co-workers have prepared a series of solids having a HKUST-1 structure in which a significant ratio of the trimesate linker is substituted by pyridine-3,5-dicarboxylate (PyDC). ${ }^{31}$ This substitution was regarded as a defect in the crystal lattice as a bridging carboxylate is replaced by a nonbridging nitrogen-donating ligand (Fig. 12). As expected by the
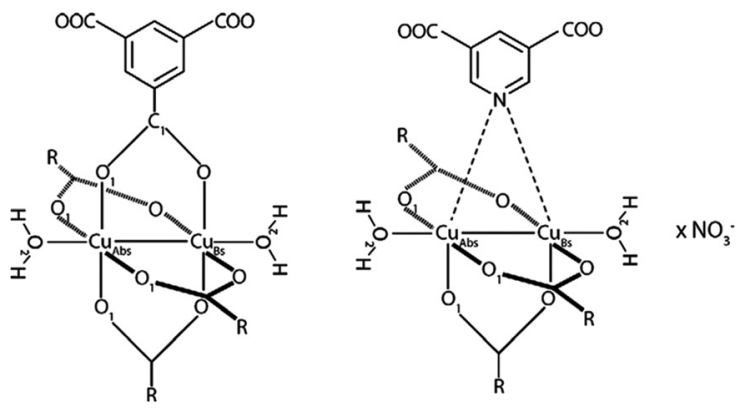

Fig. 12 Illustration of linker substitution by pyridine-3,5-dicarboxylate (PyDC) from Marx et al. ${ }^{31}$ authors, the coordination numbers of $\mathrm{Cu}$ decrease when the concentration of PyDC increases. While a coordination of 4 is expected for the parent HKUST-1, the coordination number dropped to $c a .3 .5$ for solids containing $c a$. 40\% of PyDC.

The nature of the defects at the cornerstone of HKUST-1 doped with PyDC was investigated by molecular modelling. ${ }^{31}$ The authors confirmed a significant modification of the proximate coordination space and the formation of mixed-valence $\mathrm{Cu}^{2+} / \mathrm{Cu}^{+}$paddlewheel nodes compared to the parent framework. As a result, larger binding energies relative to the parent defect-free cornerstone are measured (for CO adsorption) which can explain significant modifications of the selectivity in the toluene hydroxylation reaction using hydrogen peroxide. ${ }^{31}$ Defect engineering by PyDC doping was also recently applied to the $\mathrm{Ru}^{2+} / \mathrm{Ru}^{3+}$ analogue of HKUST-1. ${ }^{84}$ The substitution by PyDC yields materials with more strongly reduced $\mathrm{Ru}^{x+}$ species $(x \leq 2)$ as a result of partial reduction of the metal node upon increasing the carboxylate vacancies. Here also, MOFs with reduced metals demonstrated up to four times higher activity in the hydrogenation of 1-octene.

\section{Metal cation isomorphous substitution at cornerstones}

According to the approach of isomorphous substitution of linkers cited above, Dincă and co-workers have achieved isomorphous substitutions of metals at MOF cornerstones (Fig. 13). ${ }^{85}$ The authors show that metal cations with the same or different oxidation states than $2+$ can be substituted at the $\mathrm{Zn}_{4} \mathrm{O}$ cornerstone of MOF-5. MOF-5 analogues featuring $\mathrm{Cr}^{2+}$, $\mathrm{Mn}^{2+}$ and $\mathrm{Fe}^{2+}$ as well as chloride containing MOF-5 with $\mathrm{Ti}^{3+}$, $\mathrm{V}^{3+}$ and $\mathrm{Cr}^{3+}$ were obtained through a simple post-treatment of the native MOF-5 with the respective metal precursor solutions. They show that outer-sphere electron transfer is achieved in Cr-MOF-5 and that Fe-MOF-5 activates NO more than any other MOF, illustrating a unique coordination environment which makes these solids attractive for redox catalysis. ${ }^{86}$ When compared to the zeolite scene, the strategy and the resulting redox properties which have been developed here are similar to the famous example of Titanium "doped" Silicalite-1 (also called TS-1) and related solids. ${ }^{87}$ Later Cohen reported the post-synthetic metal cation exchange at the inorganic bricks of

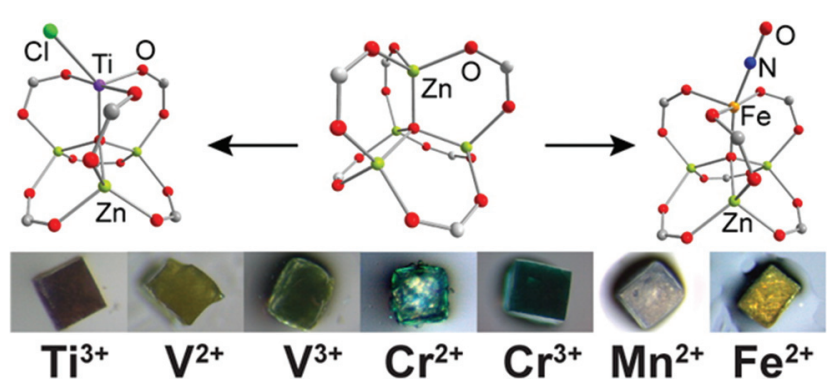

Fig. 13 Isomorphous substitution of $\mathrm{Zn}^{2+}$ by other metal cations at the $\mathrm{Zn}_{4} \mathrm{O}$ cornerstone of MOF-5 from ref. 85 . 

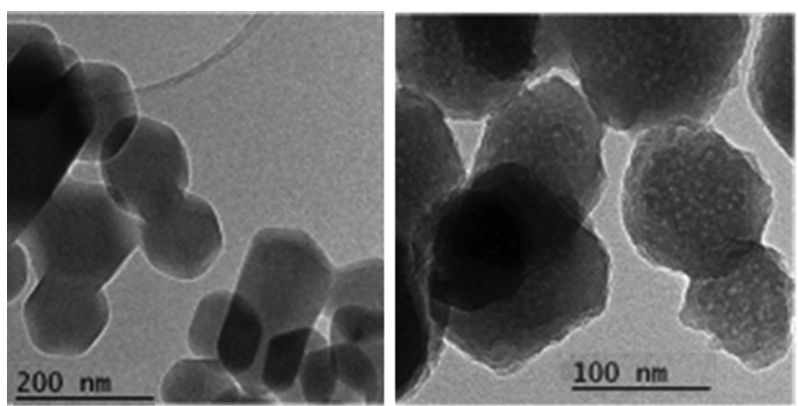

Fig. 14 TEM images of ZIF- 8 crystallites before (left) and after (right) pretreatment with oleic acid. ${ }^{90}$

MIL-53 and UiO-66 frameworks leading to mixed (Al/Fe) MIL-53-Br as well as ( $\mathrm{Zr} / \mathrm{Ti})$ and $(\mathrm{Zr} / \mathrm{Hf})$ UiO-66. ${ }^{88}$

\section{Development of micro-mesoporous hierarchical porosity}

When active sites are only accessible at the external surface of the crystallites, such as in the case of ZIF-8, the catalytic activity (for the transesterification of rapeseed oil) can be increased by either decreasing the crystallite size or by creating voids within the crystallites. The former can be obtained by using a synthesis modulator. Actually, the size of ZIF-8 crystals can be controlled from the nanometric to millimetric range by varying the precursor and modulator concentrations. ${ }^{89}$ However, nanocrystals can be hardly recovered and tested in catalytic setups. In contrast, the later approach dealing with the creation of external porosity by post-treatment processes is classically applied for zeolite catalysts (Faujasite based) that are used in fluid catalytic cracking processes. For the esterification of glycerol with oleic acid, Wee et al. have proposed a pretreatment of ZIF-8 nanocrystalline powder with a surfactant (oleic acid) in order to create internal micro-mesoporous channels within ZIF-8 crystals (Fig. 14). ${ }^{90}$

According to the study of Chizallet et al. ${ }^{73}$ it can be reasonably assumed that the active sites are located at the extended external surface of the crystallites. It was found that the micromesoporous hierarchical ZIF-8 is twice more active than very acidic zeolites (USY) and 100\% selective to the desired monoglyceride. ${ }^{90}$

\section{Conclusions}

First coined as opportunistic, the engineering of catalytic sites at the node by the creation of defects appears today as a rational approach for the design of active and selective MOF materials. ${ }^{9}$ We have shown in this Perspective article that the removal of linkers from the ideal structure either by direct methods or post-synthesis treatment is a generic strategy for the creation of defects and very active catalytic systems. The removal of ligands or linkers systematically generates surface termination which can possibly show Lewis or Brønsted features.

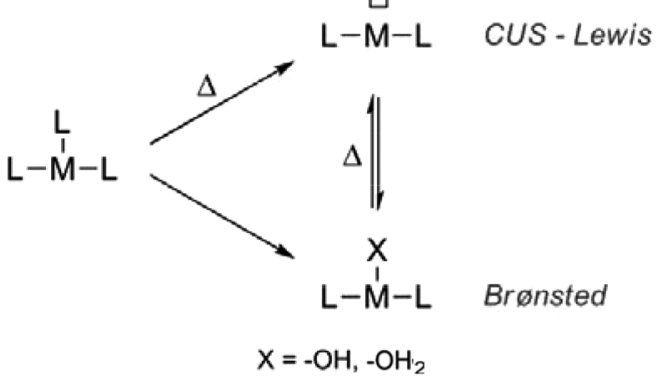

Although defective MOFs show mild acidity, we can account for very active MOFs in numerous catalytic applications with higher performances compared to zeolites or benchmark catalysts (alkylation, esterification). Remarkably, the ZIF-8 shows activity higher than state-of-the-art solids currently applied in industrial processes thanks to $\mathrm{Zn}-\mathrm{OH}$ defects likely at the external surfaces of the crystallites. Similarly to zeolite posttreatments, post-modifications of MOFs by linker or metal cation exchanges appear to be obvious methods of choice.

Despite the increasing interest in MOF-based catalysis and the outstanding recent proof of concept highlighted here, massive and systematic application of MOFs in heterogeneous catalysis at the level of zeolites is still questionable. We shall however not forget the lessons from the past. In 1860, the mineralogist Jean-Baptiste d'Omalius d'Alloy stated that "the large class of zeolites is remarkable for its tendency to show beautiful crystals, which, however, have no other use than to contribute to the glory of mineralogy collections" $\cdot+,{ }^{91}$ One and a half centuries later, even if we cannot blame him, one will agree that his vision of the fate of zeolites was unfortunate. Hence, we would not reproduce the same statement for MOFs, but we are still impatient to see breakthroughs in practice.

\section{Acknowledgements}

M.V. acknowledges funding from the Scientific Research foundation Flanders (FWO) for a postdoctoral fellowship.

\section{Notes and references}

1 O. M. Yaghi and H. Li, J. Am. Chem. Soc., 1995, 117, 10401.

2 O. M. Yaghi, H. L. Li, C. Davis, D. Richardson and T. L. Groy, Acc. Chem. Res., 1998, 31, 474.

3 O. M. Yaghi, M. O'Keeffe and M. Kanatzidis, J. Solid State Chem., 2000, 152, 1.

4 G. Ferey, J. Solid State Chem., 2000, 152, 37.

5 C. Janiak, Dalton Trans., 2003, 2781.

6 S. Kitagawa, R. Kitaura and S. Noro, Angew. Chem., Int. Ed., 2004, 43, 2334.

$\dagger$ «La grande tribu des zéolithes est remarquable par sa tendance à présenter des beaux cristaux, qui, toutefois, n'ont d'autre usage que de contribuer à l'ornement des collections de minéralogie.» Full text available online from IRIS LILLIAD - Université Lille 1 at http://iris.univ-lille1.fr. 
7 Metal-Organic Framework Materials, ed. C. M. L. Leonard and R. MacGillivray, Wiley, 2014.

8 D. Farrusseng, S. Aguado and C. Pinel, Angew. Chem., Int. Ed., 2009, 48, 7502.

9 J. Lee, O. K. Farha, J. Roberts, K. A. Scheidt, S. T. Nguyen and J. T. Hupp, Chem. Soc. Rev., 2009, 38, 1450.

10 U. Mueller, M. Schubert, F. Teich, H. Puetter, K. SchierleArndt and J. Pastre, J. Mater. Chem., 2006, 16, 626.

11 Metal-Organic Frameworks: Applications from Catalysis to Gas Storage, ed. D. Farrusseng, Wiley-VCH, Weinheim, Germany, 2011.

12 A. Corma, H. Garcia and F. X. L. I. Llabres i Xamena, Chem. Rev., 2010, 110, 4606.

13 Metal Organic Frameworks as Heterogeneous Catalysts, ed. J. Gascon, F. X. Llabres i Xamena, 2013.

14 F. X. Llabres i Xamena, A. Corma and H. Garcia, J. Phys. Chem. C, 2007, 111, 80.

15 M. E. Davis, Nature, 2002, 417, 813.

16 V. I. Isaeva and L. M. Kustov, Pet. Chem., 2010, 50, 167.

17 U. Ravon, M. E. Domine, C. Gaudillere, A. DesmartinChomel and D. Farrusseng, New J. Chem., 2008, 32, 937.

18 K. K. Tanabe and S. M. Cohen, Chem. Soc. Rev., 2011, 40, 498.

19 S. M. Cohen, Chem. Rev., 2012, 112, 970.

20 J. Canivet, S. Aguado, Y. Schuurman and D. Farrusseng, J. Am. Chem. Soc., 2013, 135, 4195.

21 J. Bonnefoy, A. Legrand, E. A. Quadrelli, J. Canivet and D. Farrusseng, J. Am. Chem. Soc., 2015, 137, 9409.

22 R. Di Monte and J. Kaspar, J. Mater. Chem., 2005, 15, 633.

23 R. Ameloot, F. Vermoortele, J. Hofkens, F. C. De Schryver, D. E. De Vos and M. B. J. Roeffaers, Angew. Chem., Int. Ed., 2013, 52, 401.

24 M. Feyand, E. Mugnaioli, F. Vermoortele, B. Bueken, J. M. Dieterich, T. Reimer, U. Kolb, D. de Vos and N. Stock, Angew. Chem., Int. Ed., 2012, 51, 10373.

25 Z. Fang, B. Bueken, D. E. De Vos and R. A. Fischer, Angew. Chem., Int. Ed., 2015, 54, 7234.

26 A. Corma, J. Catal., 2003, 216, 298.

27 C. Chizallet, M. Digne, C. Arrouvel, P. Raybaud, F. Delbecq, G. Costentin, M. Che, P. Sautet and H. Toulhoat, Top. Catal., 2009, 52, 1005.

28 C. Chizallet and P. Raybaud, ChemPhysChem, 2010, 11, 105.

29 G. C. Bond and D. T. Thompson, Catal. Rev.: Sci. Eng., 1999, 41, 319.

30 F. X. Llabres i Xamena, F. G. Cirujano and A. Corma, Microporous Mesoporous Mater., 2012, 157, 112.

31 S. Marx, W. Kleist and A. Baiker, J. Catal., 2011, 281, 76.

32 S. Vagin, A. Ott and B. Rieger, Chem. Ing. Tech., 2007, 79, 767.

33 X.-M. Lin, T.-T. Li, Y.-W. Wang, L. Zhang and C.-Y. Su, Chem. - Asian J., 2012, 7, 2796.

34 C. Prestipino, L. Regli, J. G. Vitillo, F. Bonino, A. Damin, C. Lamberti, A. Zecchina, P. L. Solari, K. O. Kongshaug and S. Bordiga, Chem. Mater., 2006, 18, 1337.

35 S. Bordiga, L. Regli, F. Bonino, E. Groppo, C. Lamberti, B. Xiao, P. S. Wheatley, R. E. Morris and A. Zecchina, Phys. Chem. Chem. Phys., 2007, 9, 2676.
36 K. Schlichte, T. Kratzke and S. Kaskel, Microporous Mesoporous Mater., 2004, 73, 81.

37 L. Alaerts, E. Seguin, H. Poelman, F. Thibault-Starzyk, P. A. Jacobs and D. E. De Vos, Chem. - Eur. J., 2006, 12, 7353.

38 A. Dhakshinamoorthy, M. Alvaro and H. Garcia, J. Catal., 2009, 267, 1.

39 Y. Wu, L.-G. Qiu, W. Wang, Z.-Q. Li, T. Xu, Z.-Y. Wu and X. Jiang, Transition Met. Chem., 2009, 34, 263.

40 K. Brown, S. Zolezzi, P. Aguirre, D. Venegas-Yazigi, V. Paredes-Garcia, R. Baggio, M. A. Novak and E. Spodine, Dalton Trans., 2009, 1422.

41 W. S. Drisdell, R. Poloni, T. M. McDonald, J. R. Long, B. Smit, J. B. Neaton, D. Prendergast and J. B. Kortright, J. Am. Chem. Soc., 2013, 135, 18183.

42 S. R. Miller, G. M. Pearce, P. A. Wright, F. Bonino, S. Chavan, S. Bordiga, I. Margiolaki, N. Guillou, G. Ferey, S. Bourrelly and P. L. Llewellyn, J. Am. Chem. Soc., 2008, 130, 15967.

43 J. A. Groves, S. R. Miller, S. J. Warrender, C. Mellot-Draznieks, P. Lightfoot and P. A. Wright, Chem. Commun., 2006, 3305.

44 L. Mitchell, B. Gonzalez-Santiago, J. P. S. Mowat, M. E. Gunn, P. Williamson, N. Acerbi, M. L. Clarke and P. A. Wright, Catal. Sci. Technol., 2013, 3, 606.

45 G. Ferey, C. Mellot-Draznieks, C. Serre, F. Millange, J. Dutour, S. Surble and I. Margiolaki, Science, 2005, 309, 2040.

46 A. G. M. Barrett and D. Christopher Braddock, Chem. Commun., 1997, 351.

47 C. O. Areán, C. P. Cabello and G. T. Palomino, Chem. Phys. Lett., 2012, 521, 104.

48 M. Opanasenko, Catal. Today, 2015, 243, 2.

49 J. Hafizovic, S. Jakobsen, U. OlsbyeOmary, N. Guillou, C. Lanberti, S. Bordiga and K. P. Lillerud, J. Am. Chem. Soc., 2008, 130, 13850.

50 L. Valenzano, B. Civalleri, S. Chavan, S. Bordiga, M. H. Nilsen, S. Jakobsen, K. P. Lillerud and C. Lamberti, Chem. Mater., 2011, 23, 1700.

51 M. Vandichel, J. Hajek, F. Vermoortele, M. Waroquier, D. E. De Vos and V. Van Speybroeck, CrystEngComm, 2015, 17, 395.

52 F. Vermoortele, B. Bueken, G. Le Bars, B. Van de Voorde, M. Vandichel, K. Houthoofd, A. Vimont, M. Daturi, M. Waroquier, V. Van Speybroeck, C. Kirschhock and D. E. De Vos, J. Am. Chem. Soc., 2013, 135, 11465.

53 G. C. Shearer, S. Forselv, S. Chavan, S. Bordiga, K. Mathisen, M. Bjorgen, S. Svelle and K. P. Lillerud, Top. Catal., 2013, 56, 770.

54 S. Oien, D. Wragg, H. Reinsch, S. Svelle, S. Bordiga, C. Lamberti and K. P. Lillerud, Cryst. Growth Des., 2014, 14, 5370 .

55 G. C. Shearer, S. Chavan, J. Ethiraj, J. G. Vitillo, S. Svelle, U. Olsbye, C. Lamberti, S. Bordiga and K. P. Lillerud, Chem. Mater., 2014, 26, 4068.

56 F. Vermoortele, M. Vandichel, B. Van de Voorde, R. Ameloot, M. Waroquier, V. Van Speybroeck and D. E. De Vos, Angew. Chem., Int. Ed., 2012, 51, 4887.

57 G. A. Olah, Friedel-Crafts Chemistry, Wiley, NY, 1973. 
58 J. S. Beck, A. D. Dandekar and T. F. Degnan, in Zeolites for cleaner technologies, ed. M. Guisnet and J. P. Gilson, Imperial College Press, London, 2002, p. 223.

59 P. Horcajada, S. Surble, C. Serre, D. Y. Hong, Y. K. Seo, J. S. Chang, J. M. Greneche, I. Margiolaki and G. Ferey, Chem. Commun., 2007, 2820.

60 A. Vimont, J. M. Goupil, J. C. Lavalley, M. Daturi, S. Surble, C. Serre, F. Millange, G. Ferey and N. Audebrand, J. Am. Chem. Soc., 2006, 128, 3218.

61 A. Vimont, H. Leclerc, F. Mauge, M. Daturi, J. C. Lavalley, S. Surble, C. Serre and G. Ferey, J. Phys. Chem. C, 2007, 111, 383.

62 L. Kurfiřtová, Y.-K. Seo, Y. K. Hwang, J.-S. Chang and J. Cejka, Catal. Today, 2012, 179, 85.

63 C. A. Fernandez, P. K. Thallapally, J. Liu and C. H. F. Peden, Cryst. Growth Des., 2010, 10, 4118.

64 L. T. L. Nguyen, C. V. Nguyen, G. H. Dang, K. K. A. Le and N. T. S. Phan, J. Mol. Catal. A: Chem., 2011, 349, 28.

65 J. Hafizovic, M. Bjorgen, U. Olsbye, P. D. C. Dietzel, S. Bordiga, C. Prestipino, C. Lamberti and K. P. Lillerud, J. Am. Chem. Soc., 2007, 129, 3612.

66 U. Ravon, G. Chaplais, C. Chizallet, B. Seyyedi, F. Bonino, S. Bordiga, N. Bats and D. Farrusseng, ChemCatChem, 2010, 2, 1235.

67 K. Soga, E. Imai and I. Hattori, Polym. J., 1981, 13, 407.

68 M. H. Chisholm, D. Navarro-Llobet and Z. P. Zhou, Macromolecules, 2002, 35, 6494.

69 M. Ree, J. Y. Bae, J. H. Jung, T. J. Shin, Y. T. Hwang and T. Chang, Polym. Eng. Sci., 2000, 40, 1542.

70 D. J. Darensbourg, M. W. Holtcamp and J. H. Reibenspies, Polyhedron, 1996, 15, 2341.

71 F. Wiesbrock and H. Schmidbaur, J. Chem. Soc., Dalton Trans., 2002, 3201.

72 U. Müller, G. Luinstra, O. M. Yaghi, O. Metelkina and M. Stößer, Process for producing polyalkylene carbonates, WO/2004/037895, 2004.

73 C. Chizallet and N. Bats, J. Phys. Chem. Lett., 2010, 1, 349.

74 D. J. Darensbourg, Chem. Rev., 2007, 107, 2388.

75 J. J. Low, A. I. Benin, P. Jakubczak, J. F. Abrahamian, S. A. Faheem and R. R. Willis, J. Am. Chem. Soc., 2009, 131, 15834.
76 J. B. DeCoste, G. W. Peterson, H. Jasuja, T. G. Glover, Y.-g. Huang and K. S. Walton, J. Mater. Chem. A, 2013, 1, 5642.

77 M. De Toni, R. Jonchiere, P. Pullumbi, F.-X. Coudert and A. H. Fuchs, ChemPhysChem, 2012, 13, 3497.

78 U. Ravon, M. Savonnet, S. Aguado, M. E. Domine, E. Janneau and D. Farrusseng, Microporous Mesoporous Mater., 2010, 129, 319.

79 S. Aguado, J. Canivet, Y. Schuurman and D. Farrusseng, J. Catal., 2011, 284, 207.

80 C. Chizallet, S. Lazare, D. Bazer-Bachi, F. Bonnier, V. Lecocq, E. Soyer, A.-A. Quoineaud and N. Bats, J. Am. Chem. Soc., 2010, 132, 12365.

81 L. M. Huang, H. T. Wang, J. X. Chen, Z. B. Wang, J. Y. Sun, D. Y. Zhao and Y. S. Yan, Microporous Mesoporous Mater., 2003, 58, 105.

82 G. Barin, V. Krungleviciute, O. Gutov, J. T. Hupp, T. Yildirim and O. K. Farha, Inorg. Chem., 2014, 53, 6914.

83 T.-H. Park, A. J. Hickman, K. Koh, S. Martin, A. G. WongFoy, M. S. Sanford and A. J. Matzger, J. Am. Chem. Soc., 2011, 133, 20138.

84 O. Kozachuk, I. Luz, F. X. Llabres i Xamena, H. Noei, M. Kauer, H. B. Albada, E. D. Bloch, B. Marler, Y. Wang, M. Muhler and R. A. Fischer, Angew. Chem., Int. Ed., 2014, 53, 7058.

85 C. K. Brozek and M. Dincă, J. Am. Chem. Soc., 2013, 135, 12886.

86 C. K. Brozek, J. T. Miller, S. A. Stoian and M. Dincă, J. Am. Chem. Soc., 2015, 137, 7495.

87 C. Perego, A. Carati, P. Ingallina, M. A. Mantegazza and G. Bellussi, Appl. Catal., A, 2001, 221, 63.

88 M. Kim, J. F. Cahill, H. Fei, K. A. Prather and S. M. Cohen, J. Am. Chem. Soc., 2012, 134, 18082.

89 S. Diring, S. Furukawa, Y. Takashima, T. Tsuruoka and S. Kitagawa, Chem. Mater., 2010, 22, 4531.

90 L. H. Wee, T. Lescouet, J. Ethiraj, F. Bonino, R. Vidruk, E. Garrier, D. Packet, S. Bordiga, D. Farrusseng, M. Herskowitz and J. A. Martens, ChemCatChem, 2013, 5, 3562 .

91 J. B. d'Omalius-d'Halloy, Minéralogie, Bruxelles, 1860. 